\section{Acesso à alimentação escolar e estado nutricional de escolares no Nordeste e Sudeste do Brasil, 1997}

\author{
Access to the school food program and \\ nutritional status of schoolchildren in Northeast \\ and Southeast Brazil, 1997
}

Luciene Burlandy 1

Luiz Antonio dos Anjos 1,2

\footnotetext{
${ }^{1}$ Departamento de Nutrição Social, Universidade Federal Fluminense, Niterói, Brasil. 2 Escola Nacional de Saúde Pública Sergio Arouca, Fundação Oswaldo Cruz, Rio de Janeiro, Brasil.

Correspondência L. A. Anjos Escola Nacional de Saúde Pública Sergio Arouca, Fundação Oswaldo Cruz. Rua Leopoldo Bulhões 1480, Rio de Janeiro, $R J$ 21041-210, Brasil. anjos@ensp.fiocruz.br
}

\begin{abstract}
Access by schoolchildren (7-10 years of age) to the School Food Program was investigated in a probabilistic sample of the Brazilian population living in the Northeast and Southeast regions in 1996-97. Among children enrolled in public schools, $87.4 \%$ had lunch at school: $77.9 \%$ in the Northeast, 93.7\% in the Southeast, and $77.9 \%$ and $90.7 \%$ in the rural and urban areas, respectively. Stunting was observed in $13.2 \%$ of children (13.8\% of boys and $12.6 \%$ of girls) and was most prevalent in the rural Northeast (22\%) and least in the urban Southeast (8.5\%). Stunting was more prevalent in children out of school (27.9\%) or enrolled in schools that did not supply lunch (17.9\%). Prevalence of overweight was relatively high (9.6\%) and similar between boys and girls, but was more prevalent in children who had lunch at school (9.8\%) as compared to children attending schools without lunch programs (5.5\%). These data suggest inadequate geographic, economic, and biological criteria in the School Food Program.
\end{abstract}

School Feeding; Nutritional Status; Nutrition Programmes

\section{Introdução}

Historicamente, ainda que sejam registradas ações governamentais na área de alimentação e nutrição já na década de 1930, estudos avaliativos de programas de nutrição são ainda escassos, e dados populacionais sobre acesso a ações públicas nesta área carecem de atualização, principalmente em sua correlação com o estado nutricional dos grupos atendidos 1,2. Em estudo anterior, analisamos a relação entre o Programa de Alimentação do Trabalhador e o estado nutricional de adultos, com dados da Pesquisa sobre Padrões de Vida (PPV) realizada pelo Instituto Brasileiro de Geografia e Estatística (IBGE), nas regiões Sudeste e Nordeste, entre março de 1996 e março de 1997 3,4. Os resultados indicaram uma inadequação entre as características do grupo atendido e o acesso a vale refeição (ou cesta básica) em ambas as regiões, visto que, do total da população ocupada, somente $19,9 \%$ recebia o benefício (24,9\% no Sudeste e $11,7 \%$ no Nordeste), concentrando-se na área urbana $(15,8 \%$ no Nordeste e 25,9\% no Sudeste), havendo aumento da freqüência no recebimento conforme a elevação da renda domiciliar per capita. Observouse um quadro de sobrepeso importante $(38,5 \%)$ particularmente no Sudeste e na área urbana ( $41 \%$; mais indivíduos com sobrepeso recebiam o benefício, quando comparados com os com baixo peso $(31,7 \%$ e $23,5 \%$, respectivamente). Usando o mesmo banco de dados da PPV, 
o presente trabalho analisou os beneficiários preferenciais de um dos programas sociais mais antigos do País, a alimentação do escolar (Programa Nacional de Alimentação Escolar - PNAE). Numa primeira aproximação ao tema, o estudo aborda de forma comparativa o acesso ao PNAE por regiões e área (urbana/rural), além do diferencial por faixas de renda, visando a identificar os grupos prioritariamente atendidos. A análise baseia-se em informações disponíveis na PPV sobre recebimento de refeição gratuita nos estabelecimentos de ensino. Num segundo momento, essas informações foram correlacionadas ao estado nutricional da população atendida, com base nos dados antropométricos dos indivíduos entrevistados.

\section{Materiais e métodos}

Os dados aqui apresentados referem-se ao conjunto de crianças na faixa etária de 7 a 10 anos, estudadas pela PPV, um inquérito populacional de base domiciliar realizado entre 1996 e 1997 nas regiões Nordeste e Sudeste do Brasil, em dez estratos geográficos, a saber: Região Metropolitana de Fortaleza, Região Metropolitana de Recife, Região Metropolitana de Salvador, restante da área urbana do Nordeste, restante da área rural do Nordeste, Região Metropolitana de Belo Horizonte, Região Metropolitana do Rio de Janeiro, Região Metropolitana de São Paulo, restante da área urbana do Sudeste e restante da área rural do Sudeste.

A amostra da pesquisa foi desenvolvida em dois estágios de seleção, com estratificação das unidades primárias (setor da base geográfica do Censo Demográfico 1991), seleção proporcional a uma medida de tamanho e seleção aleatória das unidades de segundo estágio (domicílio).

Para cada estrato geográfico, o tamanho da amostra foi fixado em 480 domicílios, 60 setores e 8 domicílios em cada setor. Excepcionalmente, para os estratos que correspondem ao restante da área rural de cada região, fixou-se em 30 o número de setores e em 16 o número de domicílios a serem selecionados por setor, em virtude da dificuldade de acesso a esses setores, o que implicaria aumento de custo 4 .

Nototal, foram investigados 19.409 indivíduos em 4.940 domicílios tanto na área urbana, quanto na rural, representando aproximadamente $70 \%$ da população nacional total, ou 103.640.611 pessoas, das quais $40,5 \%$ residentes no Nordeste e $59,5 \%$ no Sudeste, sendo $49 \%$ de homens (50.547.274) e 51\% de mulheres (53.093.337). Na faixa etária estudada (7 a 10 anos), existiam informações de 1.177 crianças (608 meninos e 569 meninas), representando, quando os valores são expandidos para a população, 6.426 .740 crianças (3.356.481, ou 52,2\% de meninos, e 3.070.259, ou $47,8 \%$ de meninas).

As informações incluídas na presente avaliação foram obtidas do CD com os microdados produzidos pelo IBGE, e são: a idade (calculada a partir da data de nascimento e de avaliação); o gênero; a freqüência a (e o tipo de) estabelecimento de ensino; a oferta de refeição gratuita na escola durante o período letivo e nas férias; a renda domiciliar per capita expressa em quintos de distribuição nacional e as medidas antropométricas (peso e estatura).

Considerando a intenção de correlacionar dados sobre o programa com informações sobre o estado nutricional da população, definiu-se a faixa etária de 7-10 anos. Essa definição, que não considera todo o período da idade escolar (7-14 anos), deve-se ao fato de que, atéos dezanos, a antropometria por si só fornece informações que permitem uma conclusão adequada quanto ao estado nutricional, podendo-se considerar que os fatores ambientais são preponderantes. Sendo assim, a partir dos dez anos, há variações significativas entre indivíduos e populações em relação a todo o processo de desenvolvimento. Dessa forma, além dos dados antropométricos, outras informações (ausentes na PPV) tornam-se fundamentais para a avaliação nutricional, como, por exemplo, o estágio de maturação sexual e medidas de composição corporal 5,6.

A avaliação nutricional foi realizada calculando-se dois índices antropométricos: o valor $\mathrm{Z}$ de estatura para a idade e o valor $Z$ de peso para a estatura, ambos em relação à curva de crescimento da população americana (NCHS, 1977), como recomendado pela Organização Mundial da Saúde (OMS) 7. Desnutrição por cada um dos índices foi estabelecida para os valores de $\mathrm{Z}<-2$. Sobrepeso foi identificado nas crianças com valor de $\mathrm{Z}$ peso para estatura $>+2$.

Os resultados de freqüências e intervalos de confiança de 95\% (IC95\%) das estimativas para a subpopulação em estudo foram obtidos com o fator de expansão calculado para a pesquisa utilizando-se a opção WEIGHT e os parâmetros de estrato (dez estratos geográficos) e de unidade primária de amostragem (setores censitários) no procedimento SURVEYFREQ do SAS (SAS Institute, Cary, Estados Unidos), dados disponíveis nos microdados fornecidos pelo IBGE. Como não havia a informação para parte das variáveis estudadas, apresenta-se o tamanho da população em todas as análises e tabelas. Cabe lembrar que a PPV é, entre as pesquisas antropométricas nacionais, a de menor amostra, o que pode proporcionar um erro maior nas estimativas. 


\section{Resultados}

Do total de crianças de 7 a 10 anos, $91,2 \%$ freqüentavam estabelecimento de ensino, sendo o percentual na Região Sudeste de 93,7\%, caindo para 83,6\% na Região Nordeste. A mais baixa freqüência se encontra na área rural do Nordeste $(80,8 \%)$ e a mais alta, na área urbana do Sudeste (97,4\%) (Tabela 1). Das 567.566 (8,8\%) crianças que não freqüentavam escola, a grande maioria (452.888) era da Região Nordeste $(79,8 \%)$, não havendo diferença entre as áreas urbana e rural: 53,9 (IC95\%: 38,4-69,5) e 46,1\% (IC95\%: 30,5$61,6)$, respectivamente. Dos não freqüentadores de escola na Região Sudeste (114.678), a grande maioria se encontrava na área urbana $(68,9 \%$; IC95\%: 50,0-87,8). Do total de crianças que freqüentava escola, 16,5\% estavam matriculadas em estabelecimentos privados e $83,5 \%$, em escolas públicas, sendo $0,7 \%$ na rede federal, $45,2 \%$ na rede estadual e $37,6 \%$ na rede municipal.

A distribuição dos estabelecimentos públicos pela rede à qual se vinculam (Federal/Estadual/Municipal) é bastante diferenciada quando os dados são analisados por regiões e área. $\mathrm{O}$ percentual de crianças que freqüenta estabelecimento de ensino municipal é extremamente mais expressivo no Nordeste rural do que no Nordeste urbano (87,9 e 28,6\% respectivamente). Mesmo quando comparada à do Sudeste rural $(49,6 \%)$, essa freqüência expressiva de escolas municipais no Nordeste rural permanece. Retirando-se desse cálculo os estabelecimentos privados, essa distribuição é ainda mais evidente $(92,6 ; 41,2$ e 49,9\% para a freqüência em escolas municipais no Nordeste rural, Nordeste urbano e Sudeste rural, respectivamente).
Do total de crianças matriculadas em escolas públicas, $87,2 \%$ freqüentavam estabelecimentos que ofereciam refeição gratuita; na Região Nordeste, esse percentual era de $77,4 \%$ e, no Sudeste, de 93,8\% (Tabela 2). De igual modo, na área rural, $77,3 \%$ dos escolares recebiam refeição, percentual que sobe para $90,7 \%$ na área urbana, reiterando o fato já amplamente conhecido de que a cobertura de serviços e programas é sempre menor na área rural e nas regiões Nordeste e Norte do país. No entanto, o diferencial regional é ainda mais grave do que o diferencial urbano/rural, considerando que, no Nordeste urbano, $83,2 \%$ das crianças estavam matriculadas em escolas que ofereciam refeição, e no Sudeste rural esse percentual sobe para 93,6\%.

A análise da oferta da alimentação escolar, segundo a vinculação do estabelecimento às redes Federal, Estadual e Municipal de ensino, indicou um papel expressivo das escolas estaduais na oferta de refeição no Nordeste rural, uma vez que $90,2 \%$ das crianças matriculadas em estabelecimentos estaduais recebiam refeição gratuita. Por outro lado, apenas $69 \%$ das crianças residentes nestas mesmas região e área freqüentavam escolas municipais que ofereciam refeição gratuita, e $71,2 \%$ do total de crianças freqüentavam estabelecimentos de ensino público que ofereciam refeição, independente da rede a que se vinculavam. Cabe ressaltar que, como visto anteriormente, 92,6\% das crianças no Nordeste rural freqüentavam estabelecimentos de ensino vinculados à rede municipal, e apenas 7,4\% estavam vinculados à rede estadual. Portanto, em termos absolutos, o número de crianças atendidas pelas escolas municipais era bastante superior, seguindo o curso da descentralização.

Distribuição (\%) e intervalos de confiança de 95\% (IC95\%) de crianças de 7 a 10 anos de idade segundo tipo de estabelecimento de ensino por região (Nordeste e Sudeste) e área (urbana e rural) do Brasil. Pesquisa sobre Padrões de Vida, 1997.

\begin{tabular}{|c|c|c|c|c|c|c|c|}
\hline \multirow[t]{2}{*}{ Região } & \multirow[t]{2}{*}{ Área } & \multirow[t]{2}{*}{$\mathbf{N}$} & \multirow[t]{2}{*}{ Freqüência } & \multicolumn{4}{|c|}{ Tipo de estabelecimento de ensino } \\
\hline & & & & Privado & Federal & Estadual & Municipal \\
\hline \multirow[t]{3}{*}{ Nordeste } & Urbana & 1.752 .735 & $87,0(80,6-93,4)$ & $30,5(23,5-37,4)$ & $0,6(0,0-1,6)$ & $40,3(32,0-48,6)$ & $28,6(21,1-36,2)$ \\
\hline & Rural & 1.178 .793 & $80,8(75,6-89,1)$ & $5,1(0,0-10,9)$ & 0,0 & $7,1(2,5-11,6)$ & $87,9(80,0-95,7)$ \\
\hline & Total & 2.931 .528 & $84,6(79,5-89,6)$ & $20,7(15,7-25,7)$ & $0,3(0,0-1,0)$ & $27,5(21,7-33,4)$ & $51,4(44,8-58,0)$ \\
\hline \multirow[t]{3}{*}{ Sudeste } & Urbana & 3.083 .445 & $97,4(95,7-99,2)$ & $15,1(10,2-19,9)$ & $1,0(0,0-2,8)$ & $59,2(51,7-66,7)$ & $24,7(18,0-31,4)$ \\
\hline & Rural & 411.767 & $91,3(86,3-96,3)$ & $0,7(0,0-1,9)$ & 0,0 & $49,(35,6-64,0) 8$ & $49,6(35,3-63,8)$ \\
\hline & Total & 3.495 .212 & $96,7(95,1-98,4)$ & $13,4(9,2-12,7)$ & $0,9(0,0-2,5)$ & $58,2(51,3-65,1)$ & $27,5(21,3-33,6)$ \\
\hline Total urbana & & 4.836 .180 & $93,7(90,9-96,4)$ & $20,2(16,2-24,3)$ & $0,9(0,0-2,1)$ & $52,9(47,0-58,7)$ & $26,0(20,9-31,1)$ \\
\hline Total rural & & 1.590 .560 & $83,6(77,2-89,9)$ & $3,8(0,0-8,0)$ & 0,0 & $19,1(13,1-25,2)$ & $77,0(69,3-84,7)$ \\
\hline Total & & 6.426 .740 & $91,2(88,6-93,8)$ & $16,5(13,3-19,8)$ & $0,7(0,0-1,6)$ & $45,2(40,3-50,1)$ & $37,6(32,9-42,3)$ \\
\hline
\end{tabular}


Na Região Sudeste, o desempenho da rede municipal, em termos de oferta de alimentação escolar, também foi inferior ao da rede Estadual na área rural. No entanto, essa diferença foi menor do que na Região Nordeste, considerando que, na área rural do Sudeste, a freqüência a estabelecimentos de ensino estaduais e municipais é semelhante, ou seja, a rede municipal não desempenha um papel tão significativo como no Nordeste rural (Tabela 2).

A oferta de refeições durante o período de férias foi pouco expressiva e seguiu a tendência verificada em relação ao período letivo no que se refere ao diferencial regional, com prevalências superiores na Região Sudeste, tanto na área urbana quanto na rural. No entanto, o diferencial por área apresentou tendência distinta, uma vez que, tanto no Sudeste, quanto no Nordeste, as prevalências na área rural são ligeiramente maiores do que na urbana (Tabela 2).

A Tabela 3 retrata a cobertura do programa em dias letivos, em termos semanais, indicando que o percentual de crianças matriculadas em estabelecimentos que ofereciam refeições de quatro a cinco dias na semana é superior ao daquelas matriculadas nos que ofereciam apenas 1 ou 2-3 dias (em ambas regiões, dados não apresentados). O diferencial regional permanece, já que, na Região Sudeste, o percentual de crianças matriculadas em escolas que ofereciam refeição 4-5 dias por semana era de 91,8, caindo para $69,9 \%$ na Região Nordeste. Igualmente, registra-se o diferencial urbano/rural (86,2\%, IC95\%: 82,1-90,4 - urbano - e 76,6\%, IC95\%: 66,3-86,8 - rural). A tendência já observada de maior acentuação para o diferencial regional também se repete: no Sudeste rural, 93,2\% (IC95\%: 87,4-95,8) das crianças estavam matriculadas em escolas que ofereciam refeição 4-5 dias por semana e, no Nordeste urbano, somente 71,7\% (IC95\%: 62,0$81,5)$.

Quanto à focalização da oferta de refeições para os grupos mais vulneráveis economicamente, percebe-se que o percentual de crianças que freqüentavam estabelecimentos com oferta de refeição cresceu conforme cresceu a renda. A distribuição das crianças por quintos de renda domiciliar per capita indicou que, nos quintos de renda mais alta, um percentual maior de crianças recebia alimentação escolar, comprometendo sensivelmente a perspectiva de eqüidade. No quinto de renda mais alta, o percentual foi de

Distribuição (\%) e intervalos de confiança de 95\% (IC95\%) de crianças de 7 a 10 anos de idade segundo oferta e freqüência de refeição gratuita por região (Nordeste e Sudeste) e área (urbana e rural) do Brasil. Pesquisa sobre Padrões de Vida, 1997.

\begin{tabular}{|c|c|c|c|c|c|c|c|c|c|c|}
\hline \multirow[t]{2}{*}{ Região } & \multirow[t]{2}{*}{ Área } & \multirow[t]{2}{*}{$\mathbf{N}$} & \multirow[t]{2}{*}{ Oferece } & \multicolumn{3}{|c|}{$\begin{array}{c}\text { Tipo de estabelecimento } \\
\text { de ensino }\end{array}$} & \multicolumn{3}{|c|}{$\begin{array}{c}\text { Número de dias da semana em } \\
\text { que é oferecida a refeição }\end{array}$} & \multirow[t]{2}{*}{$\begin{array}{l}\text { Oferta } \\
\text { nas férias }\end{array}$} \\
\hline & & & & Federal & Estadual & Municipal & 1 & $2-3$ & 4-5 & \\
\hline \multirow[t]{3}{*}{ Nordeste } & Urbana & 1.521 .252 & $\begin{array}{c}83,2 \\
(76,2-90,2)\end{array}$ & 100,0 & $\begin{array}{c}81,6 \\
(71,1-92,1)\end{array}$ & $\begin{array}{c}85,6 \\
(76,0-94,3)\end{array}$ & $\begin{array}{c}5,1 \\
(0,3-9,9)\end{array}$ & $\begin{array}{c}23,1 \\
(14,2-32,0)\end{array}$ & $\begin{array}{c}71,7 \\
(62,0-81,5)\end{array}$ & $\begin{array}{c}1,8 \\
(0,0-3,9)\end{array}$ \\
\hline & Rural & 444.179 & $\begin{array}{c}70,6 \\
(52,5-88,7)\end{array}$ & 0,0 * & $\begin{array}{c}90,2 \\
(74,1-100,0)\end{array}$ & $\begin{array}{c}69,0 \\
(49,7-88,3)\end{array}$ & $\begin{array}{c}9,7 \\
(0,0-19,9)\end{array}$ & $\begin{array}{c}22,8 \\
(8,4-37,2)\end{array}$ & $\begin{array}{c}67,4 \\
(52,5-82,4)\end{array}$ & $\begin{array}{c}2,6 \\
(0,0-5,2)\end{array}$ \\
\hline & Total & 1.965 .431 & $\begin{array}{c}77,4 \\
(68,0-86,8)\end{array}$ & 100,0 & $\begin{array}{c}82,4 \\
(72,8-92,0)\end{array}$ & $\begin{array}{c}74,6 \\
(61,1-88,0)\end{array}$ & $\begin{array}{c}7,1 \\
(1,9-12,3)\end{array}$ & $\begin{array}{c}23,0 \\
(15,3-30,9)\end{array}$ & $\begin{array}{c}69,9 \\
(61,5-78,4)\end{array}$ & $\begin{array}{c}2,1 \\
(0,5-3,8)\end{array}$ \\
\hline \multirow[t]{3}{*}{ Sudeste } & Urbana & 2.743 .964 & $\begin{array}{c}93,8 \\
(90,2-97,7)\end{array}$ & 100,0 & $\begin{array}{c}93,7 \\
(89,1-98,3)\end{array}$ & $\begin{array}{c}93,8 \\
(86,8-100,0)\end{array}$ & $\begin{array}{c}4,9 \\
(1,1-8,7)\end{array}$ & $\begin{array}{c}3,5 \\
(1,3-5,7)\end{array}$ & $\begin{array}{c}91,6 \\
(87,3-95,8)\end{array}$ & $\begin{array}{c}3,0 \\
(0,0-6,2)\end{array}$ \\
\hline & Rural & 181.725 & $\begin{array}{c}93,6 \\
(84,3-100,0)\end{array}$ & 0,0 * & $\begin{array}{c}98,7 \\
(96,1-100,0)\end{array}$ & $\begin{array}{c}88,6 \\
(70,9-100,0)\end{array}$ & $\begin{array}{c}3,9 \\
(0,0-10,1)\end{array}$ & $\begin{array}{c}2,9 \\
(0,0-6,0)\end{array}$ & $\begin{array}{c}93,2 \\
(86,4-100,0)\end{array}$ & $\begin{array}{c}4,4 \\
(0,7-8,2)\end{array}$ \\
\hline & Total & 2.925 .689 & $\begin{array}{c}93,8 \\
(90,2-97,3)\end{array}$ & 100,0 & $\begin{array}{c}94,2 \\
(90,0-98,3)\end{array}$ & $\begin{array}{c}92,8 \\
(86,0-99,5)\end{array}$ & $\begin{array}{c}4,8 \\
(1,3-8,2)\end{array}$ & $\begin{array}{c}3,4 \\
(1,5-5,4)\end{array}$ & $\begin{array}{c}91,8 \\
(88,0-95,6)\end{array}$ & $\begin{array}{c}3,2 \\
(0,3-6,0)\end{array}$ \\
\hline Total urbana & & 4.265 .216 & $\begin{array}{c}90,7 \\
(87,3-94,1)\end{array}$ & 100,0 & $\begin{array}{c}90,6 \\
(86,2-95,0)\end{array}$ & $\begin{array}{c}90,6 \\
(85,1-96,2)\end{array}$ & $\begin{array}{c}5,0 \\
(1,9-8,0)\end{array}$ & $\begin{array}{c}8,8 \\
(5,8-11,8)\end{array}$ & $\begin{array}{c}86,2 \\
(82,1-90,4)\end{array}$ & $\begin{array}{c}2,7 \\
(0,3-5,1)\end{array}$ \\
\hline Total rural & & 625.904 & $\begin{array}{c}77,3 \\
(63,9-90,8)\end{array}$ & 0,0 * & $\begin{array}{c}96,4 \\
(91,8-100,0)\end{array}$ & $\begin{array}{c}72,6 \\
(56,3-88,9)\end{array}$ & $\begin{array}{c}7,7 \\
(0,6-14,7)\end{array}$ & $\begin{array}{c}15,8 \\
(6,6-25,0)\end{array}$ & $\begin{array}{c}76,5 \\
(66,3-86,8)\end{array}$ & $\begin{array}{c}3,2 \\
(1,1-5,4)\end{array}$ \\
\hline Total & & 4.891 .120 & $\begin{array}{c}87,2 \\
(82,7-91,7)\end{array}$ & 100,0 & $\begin{array}{c}91,1 \\
(87,1-95,1)\end{array}$ & $\begin{array}{c}82,2 \\
(73,7-90,8)\end{array}$ & $\begin{array}{c}5,6 \\
(2,7-8,5)\end{array}$ & $\begin{array}{c}10,4 \\
(7,3-13,5)\end{array}$ & $\begin{array}{c}84,0 \\
(80,0-88,0)\end{array}$ & $\begin{array}{c}2,8 \\
(0,9-4,7)\end{array}$ \\
\hline
\end{tabular}

\footnotetext{
* Não há escolas federais na área rural de ambas as regiões.
} 
$95,1 \%$, ao passo que, no quinto de renda mais baixa, foi de 78,7\% (Tabela 3).

A avaliação antropométrica do estado nutricional indicou que, do total de crianças, $13,2 \%$ apresentavam desnutrição por déficit de estatura $(13,8$ e $12,5 \%$ dos meninos e meninas, respectivamente). A maior prevalência ocorreu, como esperado, no Nordeste rural (21,9\%), e a menor, no Sudeste rural $(8,4 \%)$. A prevalência na área rural é, ainda, superior à da área urbana (Tabela 4).

A desnutrição por déficit de peso foi bem baixa e, na verdade, pode-se dizer que não havia desnutrição, visto que as freqüências de valores $\mathrm{Z}<-2$ estão perto do esperado para uma popu- lação sadia (aproximadamente 2,5\%). Por outro lado, a prevalência de sobrepeso foi relativamente alta $(9,5 \%)$, sendo semelhante para meninos e meninas $(9,4 \%$ e $9,7 \%$, respectivamente). Como esperado, a maior prevalência de sobrepeso ocorreu no Sudeste urbano (15,5\%) e a menor, no Nordeste rural (2,6\%; Tabela 4).

A correlação das informações sobre desnutrição e oferta de alimentação escolar indica que houve um percentual maior de desnutrição entre crianças que não freqüentavam escolas ou que freqüentavam escolas que não ofereciam alimentação escolar (Tabela 5). O número de refeições semanais e o oferecimento de refeições durante o período de férias não pareceu estar associado à

Tabela 3

Distribuição (\%) e intervalos de confiança de 95\% (IC95\%) de crianças de 7 a 10 anos segundo oferta e freqüência de refeição gratuita por quinto de renda domiciliar per capita. Pesquisa sobre Padrões de Vida, 1997.

\begin{tabular}{|c|c|c|c|c|c|c|}
\hline \multirow[t]{2}{*}{$\begin{array}{l}\text { Quinto de renda } \\
\text { domiciliar per capita }\end{array}$} & \multirow[t]{2}{*}{$\mathbf{N}$} & \multirow[t]{2}{*}{ Oferece } & \multicolumn{3}{|c|}{$\begin{array}{l}\text { Número de dias da semana } \\
\text { em que é oferecida a refeição }\end{array}$} & \multirow[t]{2}{*}{$\begin{array}{l}\text { Oferece } \\
\text { nas férias }\end{array}$} \\
\hline & & & 1 & $2-3$ & $4-5$ & \\
\hline 1으 & 1.508 .232 & $78,7(68,2-89,2)$ & $8,3(2,0-14,5)$ & $16,7(8,5-24,9)$ & $75,0(65,6-84,6)$ & $1,9(0,0-, 38)$ \\
\hline 2으 & 1.065 .503 & $88,9(83,4-94,4)$ & $5,0(0,0-10,3)$ & $10,7(5,4-16,1)$ & $84,2(77,0-91,4)$ & $1,6(0,5-2,8)$ \\
\hline 3으 & 912.648 & $92,5(87,2-97,7)$ & $2,4(0,0-4,8)$ & $5,0(0,6-8,3)$ & $92,6(88,2-97,1)$ & $6,5(0,0-14,0)$ \\
\hline 4으 & 680.289 & $91,0(82,7-99,2)$ & $10,0(0,1-19,8)$ & $6,5(0,6-11,4)$ & $83,5(73,1-93,9)$ & $0,9(0,0-1,9)$ \\
\hline 5으 & 381.111 & $95,1(89,2-100,0)$ & $0,2(0,0-0,7)$ & $7,6(0,0-17,6)$ & $92,1(82,1-100,0)$ & $6,0(0,0-16,9)$ \\
\hline Total & 4.547 .783 & $87,1(82,6-91,5)$ & $5,8(2,8-8,7)$ & $10,4(7,1-13,6)$ & $83,9(79,9-87,8)$ & $3,0(1,0-5,1)$ \\
\hline
\end{tabular}

Tabela 4

Prevalência (\%) e intervalos de confiança de 95\% (IC95\%) de crianças de 7 a 10 anos segundo o estado nutricional por região (Nordeste e Sudeste) e área (urbana e rural) do Brasil. Pesquisa sobre Padrões de Vida, 1997.

\begin{tabular}{|c|c|c|c|c|c|c|}
\hline Região & Área & $\begin{array}{c}\mathrm{N} \text { total de medidas } \\
\text { de estatura }\end{array}$ & $\begin{array}{c}\text { Desnutrição por } \\
\text { déficit de estatura * }\end{array}$ & $\begin{array}{c}\mathrm{N} \text { total de } \\
\text { medidas de peso }\end{array}$ & $\begin{array}{l}\text { Desnutrição por } \\
\text { déficit de peso ** }\end{array}$ & Sobrepeso *** \\
\hline \multirow[t]{3}{*}{ Nordeste } & Urbana & 1.558 .601 & $10,5(5,9-15,1)$ & 1.504 .061 & $2,2(0,0-4,9)$ & $5,4(1,9-8,0)$ \\
\hline & Rural & 1.070 .179 & $21,9(12,3-31,5)$ & 1.070 .067 & $1,4(0,0-3,0)$ & $2,6(0,4-4,8)$ \\
\hline & Total & 2.628 .780 & $15,1(10,1-20,1)$ & 2.574 .128 & $1,9(0,2-3,6)$ & $4,2(2,0-6,5)$ \\
\hline \multirow[t]{3}{*}{ Sudeste } & Urbana & 2.820 .160 & $12,0(7,8-16,2)$ & 2.295 .991 & $1,5(0,0-3,1)$ & $15,5(10,8-20,2)$ \\
\hline & Rural & 404.044 & $8,4(3,8-13,0)$ & 364.135 & $5,3(1,7-8,9)$ & $9,1(3,6-14,6)$ \\
\hline & Total & 3.224 .204 & $11,6(7,9-15,3)$ & 2.660 .126 & $2,0(0,6-3,5)$ & $14,6(10,5-18,8)$ \\
\hline Total urbana & & 4.378 .761 & $11,5(8,3-14,6)$ & 3.800 .052 & $1,8(0,4-3,2)$ & $11,5(8,3-14,8)$ \\
\hline Total rural & & 1.474 .223 & $18,2(10,9-25,5)$ & 1.434 .202 & $2,4(0,8-3,9)$ & $4,2(2,1-6,3)$ \\
\hline Total & & 5.852 .984 & $13,2(10,1-16,2)$ & 523.454 & $2,0(0,8-, 31)$ & $9,5(7,1-12,0)$ \\
\hline
\end{tabular}

* Z estatura para a idade $<-2$;

$\star \star Z$ peso para estatura $<-2$;

$\star \star \star Z$ peso para estatura $>+2$. 
Prevalência (\%) e intervalos de confiança de 95\% (IC95\%) de crianças de 7 a 10 anos segundo o estado nutricional por freqüência à escola e oferta e freqüência de refeição gratuita. Pesquisa sobre Padrões de Vida, 1997.

\begin{tabular}{|c|c|c|c|c|c|}
\hline & $\mathbf{N}$ & $\begin{array}{c}\text { Desnutrição por } \\
\text { déficit de estatura * }\end{array}$ & $\mathbf{N}$ & $\begin{array}{l}\text { Desnutrição por déficit } \\
\text { de peso para estatura ** }\end{array}$ & Sobrepeso $\star \star \star$ \\
\hline \multicolumn{6}{|c|}{ Freqüência à escola } \\
\hline $\operatorname{Sim}$ & 5.325 .136 & $11,7(8,6-14,9)$ & 4.736 .900 & $2,0(0,8-3,2)$ & $9,2(6,9-11,7)$ \\
\hline Não & 527.848 & $27,7(16,8-38,6)$ & 497.354 & $1,3(0,0-3,7)$ & $11,9(3,4-20,4)$ \\
\hline Total & 5.852 .984 & $13,2(10,1-16,2)$ & 5.234 .254 & $2,0(0,8-3,1)$ & $9,5(7,1-12,0)$ \\
\hline \multicolumn{6}{|c|}{ Oferta de refeição } \\
\hline Sim & 3.875 .189 & $11,8(8,5-15,0)$ & 3.424 .891 & $2,2(1,0-3,5)$ & $9,9(6,9-12,9)$ \\
\hline Não & 569.780 & $17,9(1,0-34,0)$ & 552.631 & $1,7(0,0-5,0)$ & $5,5(0,0-11,0)$ \\
\hline Total & 4.444 .969 & $12,6(8,9-16,2)$ & 3.977 .522 & $2,2(1,0-3,3)$ & $9,3(6,6-12,0)$ \\
\hline \multicolumn{6}{|c|}{ Número de refeições por semana } \\
\hline 1 & 174.049 & $12,0(0,0-28,1)$ & 163.225 & 0,0 & $10,2(0,0-24,1)$ \\
\hline $2-3$ & 419.128 & $14,3(4,6-24,1)$ & 400.597 & $2,8(0,0-6,7)$ & $5,1(0,0-11,4)$ \\
\hline $4-5$ & 282.012 & $11,5(8,0-14,9)$ & 2.861 .069 & $2,3(0,9-3,7)$ & $10,5(7,1-13,9)$ \\
\hline Total & 3.875 .189 & $11,8(8,2-15,0)$ & 3.424 .891 & $2,2(1,0-3,5)$ & $9,9(6,9-12,8)$ \\
\hline \multicolumn{6}{|c|}{ Oferecimento de refeições nas férias } \\
\hline Sim & 120.507 & $15,0(0,0-37,7)$ & 110.796 & 0,0 & $16,0(0,0-40,4)$ \\
\hline Não & 3.754 .682 & $11,7(8,3-15,0)$ & 3.314 .095 & $2,3(1,0-3,6)$ & $9,7(6,6-12,7)$ \\
\hline Total & 3.875 .189 & $11,8(8,5-15,0)$ & 3.424 .891 & $2,2(1,0-3,5)$ & $9,7(6,9-12,8)$ \\
\hline
\end{tabular}

* Z estatura para a idade $<-2$;

** $Z$ peso para estatura $<-2$;

$\star \star \star Z$ peso para estatura $>+2$.

prevalência de desnutrição por déficit de estatura, decorrente, em parte do fato da baixa oferta de refeições nas férias.

\section{Discussão}

A análise da oferta de refeição gratuita nas escolas, a partir dos dados da PPV, indica uma cobertura superior do programa na Região Sudeste, quando comparada à cobertura no Nordeste; é superior também nas áreas urbanas em relação às rurais, seguindo a tendência já indicada em estudos avaliativos desenvolvidos nas décadas de 70 e 80. Tais estudos, apesar de escassos, são unânimes em destacar que os programas na área de políticas de alimentação e nutrição, particularmente os de suplementação alimentar, conjugavam ineficácia, clientelismo, impacto reduzido, baixo desempenho, o não alcance efetivo dos grupos mais vulneráveis, além de uma cobertura real inferior à anunciada oficialmente $2,8,9,10$. Os coeficientes de atendimento por regiões e por faixas de renda expressavam uma situação pouco favorável em relação ao princípio da eqüidade 8,9, já que a população residente em áreas com maio- res percentuais de desnutrição, como o Norte e o Nordeste rural, tinha menor acesso às intervenções públicas 11 .

A operacionalização desses programas tradicionalmente apresentou uma série de intercorrências que comprometeram sua eficácia, como um desempenho muito instável em termos de recursos (atraso no repasse e reduções constantes), incompatível com o volume da clientela atendida e metas de atendimento, além de deturpações nos mecanismos de compra e pouca possibilidade de controle social sobre sua operacionalização ${ }^{8}$. O desempenho dessa política é ainda mais limitado na conjuntura atual, pela diferenciação crescente de situações de risco social e em saúde, em face das transformações no padrão de vida e consumo, além da complexidade do quadro nutricional da população brasileira, no qual convivem problemas como desnutrição e obesidade 11 .

O PNAE vem se destacando como um dos mais tradicionais no setor, tendo suas raízes na década de 1930 quando, ainda em âmbito privado, as escolas ofereciam refeições para os alunos, financiadas por fundos advindos das caixas escolares. Na década de 1950, o programa assumiu 
o caráter de "campanha nacional", subsistindo a partir de doações internacionais, e se expandiu a partir da década de 70, concomitante com um processo de centralização do programa em nível federal.

Somente a partir de meados dos anos 1980, a proposta de descentralização ganha fôlego, e, em 1992, o Governo Federal passa a transferir recursos financeiros aos estados, possibilitando maior adaptação dos cardápios à realidade cultural local e o consumo de frutas, verduras e legumes frescos, no lugar dos alimentos industrializados.

Em 1979, o PNAE atendeu a apenas 70\% dos 180 dias letivos; no Nordeste, a situação era pior, considerando que os estudantes receberam alimentação em somente 97 dias letivos (pouco mais de 50\%). Em 1981, esse percentual se ampliou, tendo sido atendidos 111 dias letivos no Nordeste e 161 no Sudeste, para uma média nacional de 135 dias 12 .

Uma análise do PNAE para o período de 19801986 indica que, apesar da ampliação da clientela atendida, a quantidade de alimentos distribuídos e os recursos despendidos não seguiram a mesma proporção, deteriorando a qualidade do atendimento. Em 1986, além dos estudantes matriculados na rede pública e filantrópica de escolas de ensino fundamental e de educação infantil, o programa incorporou ao seu atendimento crianças menores de seis anos que fossem irmãs desses escolares, representando, ao final desse mesmo ano, $25 \%$ de toda a população. Nesse período, também se intensificou a demanda pela descentralização do programa, desenvolvendose uma experiência-piloto de sua municipalização em 200 municípios, que não redundou em implantação do processo propriamente dito 13 .

A partir de 1993, a descentralização do programa operacionalizou-se por intermédio da Fundação de Assistência ao Estudante (FAE), seguindo modalidades diferentes de repasse de recursos: diretamente para os municípios que aderiram à descentralização ou para as secretarias estaduais que atendem crianças não incluídas nos serviços geridos pelas prefeituras 14 .

A avaliação do PNAE, valendo-se dos dados da Pesquisa Nacional sobre Saúde e Nutrição (PNSN), inquérito domiciliar realizado em 1989, indicou que, naquela conjuntura, $78 \%$ das crianças matriculadas em escolas públicas de ensino fundamental recebiam alimentação. A Região Sudeste apresentava maior cobertura $(91 \%$ dos alunos matriculados); a Região Nordeste, a menor $(57 \%)$. No que se refere ao diferencial entre extratos urbano/rural, em todas as regiões, em média $83 \%$ dos alunos matriculados em escolas urbanas eram atendidos, percentual que se reduzia para $69 \%$ nas escolas rurais. Quanto à freqüência na distribuição de refeições, nas regiões Sudeste e Sul, $80 \%$ das escolas que ofereciam alimentação o faziam em quatro ou mais dias por semana, enquanto na Região Nordeste esse percentual decrescia para $57 \% 8$.

Em relação a esses achados, os dados da PPV, avaliados no presente estudo, sugerem que não houve alteração significativa em termos de perfil de distribuição percentual entre as regiões e estratos no período de 1989-1997, tendo havido incremento no percentual de oferta de refeições em todos os segmentos, particularmente na cobertura no Nordeste ( $57 \%$ para $77,4 \%$ na PPV) e na freqüência de oferta de refeições também no Nordeste $(57 \%$ para aproximadamente $70 \%$ das crianças recebendo quatro a cinco refeições semanais na PPV).

As análises prévias do PNAE indicam que o atendimento também era desigual no que se refere à focalização nos grupos mais vulneráveis economicamente, visto que, nos segmentos de renda mais baixa, $63 \%$ dos escolares freqüentavam estabelecimentos de ensino que ofereciam alimentação escolar, ao passo que, nas classes de renda mais alta, esse percentual era de $83 \%$. Os dados da PPV indicam que a focalização ainda é inadequada, considerando que a cobertura do programa é diretamente proporcional à renda, ou seja, a população situada nos quintos de renda mais alta tem maior acesso à oferta de refeições nas escolas.

Em 1997, o volume de recursos da alimentação escolar repassado para estados e municípios correspondeu a $93,5 \%$ da meta inicial, equivalendo a 168 dias letivos, e $73 \%$ dos municípios brasileiros celebraram convênios de municipalização, atendendo a $59 \%$ da clientela total do programa 15 . As principais dificuldades encontradas, segundo avaliação da Comunidade Solidária, referem-se a irregularidades no repasse de recursos, insuficiência para suprir os 180 dias letivos e, em determinados municípios, aos próprios limites de acesso físico, considerando a precariedade das estradas, o que dificulta o transporte dos alimentos 16 .

Em termos de freqüência à escola, dados da Pesquisa Nacional por Amostra de Domicílios (PNAD) de 1981 e 1989 indicam que, em 1981, $70,3 \%$ das crianças de 7-14 anos freqüentavam escola, percentual que se elevou para $83,9 \%$ em 1989. Essa ampliação ocorreu tanto nas áreas urbanas, quanto nas rurais (onde foi ainda mais expressiva - de $47,2 \%$ para $72,1 \%$ ), superando o crescimento populacional dessa faixa etária. Outros estudos vêm sinalizando um aumento expressivo e generalizado das taxas de escolarização, permanecendo, no entanto, as diferenças regionais e por extratos urbano/rural 17,18,19, 
também evidentes na presente análise da PPV, que documentou $91,2 \%$ das crianças freqüentando escolas em ambas as regiões, mas com um valor diferencial de aproximadamente $10 \%$ entre as regiões e áreas rural/urbana.

No que se refere mais especificamente à faixa etária do escolar, análises de âmbito nacional sobre o estado nutricional deste segmento são bastante escassas. Estudos desse porte normalmente focalizam a situação de crianças menores do que cinco anos ou de escolares de regiões/cidades específicas no país. Por exemplo, numa amostra representativa de escolares do Município do Rio de Janeiro, Anjos et al. 20 encontraram prevalências bastante baixas de desnutrição por déficit de estatura (1,9 e 2,8\% para meninas e meninos até dez anos de idade, respectivamente) e valores bem maiores de sobrepeso para essa faixa etária tanto para meninas $(6,3 \%)$, quanto para meninos $(7,7 \%)$. Análise dos dados da PNSN indicou um percentual de $12,9 \%$ de desnutrição por déficit de estatura em crianças brasileiras de 6 a 10 anos, sendo as maiores prevalências encontradas nas regiões Nordeste e Norte 21 . A prevalência de sobrepeso nessa faixa etária no Brasil como um todo, na PNSN, foi de 4,8\% 22. A correlação com o estado nutricional reitera a inadequação do processo de focalização no que se refere à vulnerabilidade biológica, uma vez que são justamente as localidades que concentram os percentuais mais elevados de desnutrição (Região Nordeste e área rural) as que registram os percentuais mais baixos de acesso ao programa.

Cabe ressaltar que a focalização adequada do PNAE depende, em grande medida, da cobertura da rede de ensino, porque é através da escola que este programa se operacionaliza. Os resultados deste estudo indicaram que o déficit de estatura/idade foi mais prevalente em crianças que não freqüentavam escolas, em ambas as regiões analisadas; portanto, o alcance deste segmento mais vulnerável por meio da alimentação escolar implica, antes de tudo, sua inserção nas instituições de ensino. Esse déficit também foi maior em crianças que freqüentavam escolas que não ofereciam alimentação. Nesse caso, um aprimoramento do processo de implementação do programa pode impactar positivamente o alcance desses segmentos, independentemente de uma ampliação da cobertura da rede escolar.

Por fim, é importante considerar que o quadro aqui descrito pode ser alterado diante das recentes modificações nos parâmetros operacionais do PNAE, que sinalizam possíveis conseqüências em termos de cobertura e focalização do programa, tais como: o aumento no valor per capita repassado pelo governo federal aos municípios (no ensino fundamental os valores passaram de $\mathrm{R} \$ 0,13$ para $\mathrm{R} \$ 0,18$ em 2005 chegando a R\$ 0,22 em 2006); a equiparação com o ensino fundamental do repasse per capita de recursos para o pré-escolar; a extensão do atendimento para alunos indígenas, com valores per capita três vezes maiores do que o da rede básica; o atendimento a creches públicas e filantrópicas a partir de 2003, que também passaram a receber, em 2006, o valor per capita de R $\$$,22; o repasse para escolares em comunidades quilombolas a partir de 2005, num valor de $\mathrm{R} \$ 0,34$, que aumentou para R\$ 0,44 em 2006. Além das alterações nos valores repassados, foi elaborado um pré-projeto de lei pelo Conselho Nacional de Segurança Alimentar e Nutricional (CONSEA) que abre possibilidades para a ampliação de cobertura do programa para o ensino médio, fortalece as ações de promoção da alimentação saudável e adequada nas escolas e garante condições para compra de alimentos diretamente da agricultura familiar 23,24. Outra questão a ser considerada refere-se à própria cobertura da rede de ensino, visto que a comparação dos resultados das PNAD ao longo das ultimas décadas indica que houve aumento significativo na escolarização de crianças e adolescentes 25 . Esse conjunto de fatores pode ter implicações importantes na ampliação da cobertura do programa, repercutindo positivamente no alcance dos segmentos mais vulneráveis, o que indica a relevância de análises comparativas subseqüentes ao presente estudo.

Em síntese, conclui-se que a oferta de refeição gratuita nas escolas no período estudado, em termos de focalização aos grupos prioritários, foi inadequada quanto aos critérios geográficos, econômicos e biológicos, apesar da aparente melhora na sua cobertura. 


\section{Resumo}

Com base na Pesquisa sobre Padrões de Vida de 1996/1997, realizada nas regiões Sudeste e Nordeste do Brasil, analisaram-se informações sobre oferta de refeição gratuita nas escolas e antropometria de crianças de 7-10 anos. Daquelas matriculadas em escolas públicas, $87,4 \%$ freqüentavam estabelecimentos que ofereciam refeição gratuita, sendo 77,9\% no Nordeste; 93,7\% no Sudeste; 77,9\% na área rural e 90,7\% na área urbana. A oferta nas escolas municipais foi inferior à das estaduais, principalmente no Nordeste rural (90,2\% nas estaduais e 69,6\% nas municipais). Do total de crianças, 13,2\% apresentavam desnutrição por déficit de estatura (13,8\% meninos; $12,6 \%$ meninas), com maior prevalência no Nordeste rural (22\%) e menor no Sudeste rural (8,5\%). A prevalência de sobrepeso foi expressiva (9,6\%), maior no Sudeste urbano $(15,6 \%)$ e menor no Nordeste rural (2,7\%). A desnutrição foi prevalente entre crianças que não freqüentavam escolas $(27,9 \%$ vs. $11,8 \%)$ ou em escolas que não ofereciam refeição gratuita (17,9\% vs. $11,8 \%)$; o sobrepeso foi prevalente em crianças que recebiam refeição gratuita (9,8\% vs. 5,5\%). Percebe-se uma focalização inadequada da oferta quanto aos critérios geográficos, econômicos e biológicos.

Alimentação Escolar; Estado Nutricional; Programas de Nutrição

\section{Referências}

1. L’Abbate S. As políticas de alimentação e nutrição no Brasil a partir dos anos setenta. Rev Nutr PUCCAMP 1989; 2:7-54.

2. Valente F. Inserção dos componentes de alimentação e nutrição nas políticas governamentais e na estratégia internacional de desenvolvimento. Brasília: Organização das Nações Unidas para Agricultura e Alimentação; 1996.

3. Burlandy L, Anjos LA. Acesso a vale-refeição e estado nutricional de adultos beneficiários do Programa de Alimentação do Trabalhador no Nordeste e Sudeste do Brasil, 1997. Cad Saúde Pública 2001; 17:1457-64.

4. Instituto Brasileiro de Geografia e Estatística. Pesquisa sobre padrões de vida. Brasília: Instituto Brasileiro de Geografia e Estatística; 1998.

5. Duarte MFS. Maturação física: uma revisão da literatura, com especial atenção à criança brasileira Cad Saúde Pública 1993; 9 Suppl 1:S71-84.

6. Roche AF, Siervogel RM, Chumlea C, Webb P. Grading body fatness from limited anthropometric data. Am J Clin Nutr 1981; 34:2831-8.

\section{Colaboradores}

L. A. Anjos foi responsável pelas análises estatísticas da Pesquisa sobre Padrões de Vida. Coube à L. Burlandy o levantamento sobre o histórico dos programas da área de alimentação e nutrição. Os autores são responsáveis por todos os aspectos de revisão, preparação e escrita.

\section{Agradecimentos}

Luiz Antonio dos Anjos recebeu bolsa de produtividade do Conselho Nacional de Desenvolvimento Científico e Tecnológico (CNPq - processo no. 301076/89-8).
7. World Health Organization. Physical status: the use and interpretation of anthopometry. Geneva: World Health Organization; 1995. (WHO Technical Report Series, 854)

8. Peliano AMTM. Quem se beneficia dos programas governamentais de suplementação alimentar. Brasília: Instituto de Pesquisa Econômica Aplicada; 1990. (Texto para Discussão, 205).

9. Peliano AMTM, Beghin N. Os programas de alimentação e nutrição para as crianças e adolescentes, qual o destino? Brasília: Instituto de Pesquisa Econômica Aplicada; 1992.

10. Peliano AMTM. Os programas alimentares e nutricionais no contexto da recessão econômica: 19801984. In: Chahad JP, Cervini R, organizadores. Crise e infância no Brasil. O impacto das políticas de ajuste econômico. São Paulo: Fundo das Nações Unidas para a Infância/Fundação Instituto de Pesquisas Econômicas/Universidade de São Paulo; 1988. p. 139-84. 
11. Monteiro CA. Velhos e novos males da saúde no Brasil: evolução do país e suas doenças. São Paulo: Hucitec/Universidade de São Paulo; 1995.

12. Torres Filho E, Carvalho ME. Uma análise dos programas de suplementação alimentar nos anos 80: desempenho e formas de organização. In: Ministério da Previdência e Assistência Social/Comissão Econômica para a América Latina e o Caribe, organizadores. Política social em tempo de crise: articulação institucional e descentralização. Economia e desenvolvimento 6. v. II. Brasília: Ministério da Previdência e Assistência Social/Comissão Econômica para a América Latina e o Caribe; 1989.

13. Instituto de Pesquisa Econômica Aplicada. Um balanço das ações de governo no combate à fome e à miséria - 1993. Brasília: Instituto de Pesquisa Econômica Aplicada; 1994.

14. Instituto de Pesquisa Econômica Aplicada. Comunidade Solidária. Informe a XIX Reunião do Conselho. Relatório das Ações Governamentais em 1997. Brasília: Instituto de Pesquisa Econômica Aplicada; 1998.

15. Instituto de Pesquisa Econômica Aplicada. Comunidade Solidária. Informe a XII Reunião do Conselho: um relato das ações de governo em 1996. Brasília: Instituto de Pesquisa Econômica Aplicada; 1997.

16. Instituto Brasileiro de Administração Municipal/ Instituto de Pesquisa Econômica Aplicada/Programa das Nações Unidas para o Desenvolvimento. Avaliação da estratégia do Comunidade Solidária. Rio de Janeiro: Instituto Brasileiro de Administração Municipal/Instituto de Pesquisa Econômica Aplicada/Programa das Nações Unidas para o Desenvolvimento; 1998

17. Instituto Brasileiro de Geografia e Estatística/Fundo das Nações Unidas para a Infância. Municípios brasileiros: crianças e suas condições de sobrevivência. Brasília: Instituto Brasileiro de Geografia e Estatística; 1994
18. Bem-Estar Familiar no Brasil. Pesquisa nacional sobre demografia e saúde. Brasília: Bem-Estar Familiar no Brasil; 1996.

19. Programa das Nações Unidas para o Desenvolvimento. Municípios brasileiros: índice de condições de vida. Brasília: Programa das Nações Unidas para o Desenvolvimento; 1998.

20. Anjos LA, Castro IRR, Engstrom EM, Azevedo AMF Crescimento e estado nutricional em amostra probabilística de escolares no Município do Rio de Janeiro, 1999. Cad Saúde Pública 2003; 19 Suppl 1: S171-9.

21. Engstrom EM, Anjos LA. Relação entre o estado nutricional materno e sobrepeso nas crianças brasileiras. Rev Saúde Pública 1996; 30:233-9.

22. Engstrom EM, Anjos LA. Déficit estatural nas crianças brasileiras: relações com condições sócio-ambientais e estado nutricional materno. Cad Saúde Pública 1999; 15:559-67.

23. Fundo Nacional de Desenvolvimento da Educação. FNDE libera parcela da alimentação escolar com aumento. http://www.planalto.gov.br/CONSEA (acessado em 20/Out/2006).

24. Conselho Nacional de Segurança Alimentar e Nutricional. As novidades da merenda em 2003 e as perspectivas para 2004. In: Encontro Nacional de Segurança Alimentar e Nutricional. http://www. fnde.gov.br/programa/pnae (acessado em 10/ Mar/2004).

25. Instituto Brasileiro de Geografia e Estatística. Acesso a transferências de renda de programas sociais, 2004: aspectos complementares de educação e acesso à transferência de renda de programas sociais. Brasília: Instituto Brasileiro de Geografia e Estatística; 2005.

Recebido em 10/Out/2005

Versão final reapresentada em 30/Out/2006

Aprovado em 28/Out/2006 